Case Report

\title{
COMMUNICATION BETWEEN THE MUSCULOCUTANEOUS AND MEDIAN NERVE : OCCURRENCE ON BOTH SIDES
}

\author{
Remya $K^{1}$, Ashwin Krishnamurthy ${ }^{2}$, Kavitha $K^{1}$ \\ ${ }^{1}$ K.S. Hegde M edical Academy, Nitte University, M angalore - 575018, ${ }^{2}$ Kasturba M edical College, M angalore - 575001 \\ Correspondence: \\ Remya K. \\ E-mail : remya_285@yahoo.co.in
}

\begin{abstract}
:
Communications between musculocutaneous nerve and median nerve may be of considerable significance to neurologists and orthopaedicians when dealing with patients of nerve entrapment syndromes of the upper limb. M any authors have mentioned about an occurrence of such a variation previously, but the presence of a communication between the two nerves in both the arms has not been cited to the best of our knowledge. During routine dissection on a 72 year old male cadaver for the under graduate students in the Department of Anatomy at K.S. Hegde M edical Academy, we encountered an anomalous communication between musculocutaneous and median nerve in both the upper limbs. The communicating branch arose from the musculocutaneous nerve at a distance of $12.6 \mathrm{~cm}$ and $12.5 \mathrm{~cm}$ from the tip of coracoid process on right and left side and joined the median nerve $16.2 \mathrm{~cm}$ from the same bony point. Communications between nerves like this may explain abnormal debilities in certain cases of trauma of the upper arm. Lack of awareness of such variations with different patterns of communications between musculocutaneous and median nerve might complicate surgical repair of the nerves.
\end{abstract}

\section{Introduction}

Amongst the several variations noted with the formation, course and distribution of the roots, cords and branches of the brachial plexus is the communication of the musculocutaneous and median nerve.M any authors have mentioned about an occurrence of such a variation previously, but the presence of a communication between the two nerves in both the arms has not been cited to the best of our knowledge. The median nerve is formed by union of two roots from the lateral $\left(C_{5,6,7}\right)$ and medial $\left(C_{8}, T_{1}\right)$ cords while the musculocutaneous nerve $\left(C_{5,6,7}\right)$ arises from the lateral cord of the brachial plexus ${ }^{1,2}$. According to Tountas and Bergaman (1993), the musculocutaneous nerve arises from the lateral cord in $90.5 \%$, from the lateral and posterior cord in $4 \%$, from the medial cord in $2 \%$ and has two separate bundles from the medial and lateral cords in $1.4 \%$. Sometimes it sends a branch back to the median nerve in the brachium (Williams et al., 1999; Arora and Dhingra, 2005). Williams et al. (1999) stated that some fibres of the median nerve may run in the musculocutaneous nerve leaving it to join their main trunk.

Musculocutaneous nerve ( $\mathrm{MCN}$ ) is the branch from the lateral cord of the brachial plexus. The nerve initially accompanies the axillary artery, pierces the coracobrachialis muscle, and then passes downwards between the biceps brachii and brachialis. It supplies coracobrachialis, biceps brachii and medial part of brachialis muscles. Below the elbow joint the nerve is continuous as the lateral cutaneous nerve of the forearm

\section{Case Report}

During the routine anatomy dissections, we encountered an anomalous communication between musculocutaneous and median nerve in both the upper limbs of a 72 year old male cadaver from the collections in the Department of Anatomy, K.S. Hegde Medical Academy. The communicating branch arose from the musculocutaneous nerve at a distance of $12.6 \mathrm{~cm}$ and 12.5 $\mathrm{cm}$ from the tip of coracoid process on right and left side and joined the median nerve $16.2 \mathrm{~cm}$ from the same bony point. Further course and relations of $\mathrm{M} \mathrm{CN}$ were found to be without any variation.

\section{Discussion :}

Communication between the branches of brachial plexus is a common phenomenon. The present case reveals the presence of a communication between the two nerves in both the arms which is so far not been cited to the best of 
our knowledge. Several anomalous branches between the musculocutaneous nerve and median nerve had been reported by authors like Venieratos et $\mathrm{al}^{3}$, Eglseder et $\mathrm{al}^{4}$, Loukas et al ${ }^{5}$, Prasada Rao et al ${ }^{6}$, Chauhan et al ${ }^{7}$. Kerr found that a branch from the musculocutaneous nerve to the median had been reported in $8.1 \%$ to $36.19 \%$ of different series and estimated its incidence as somewhat less than the $24 \%$ found in his series. Venieratos et al had classified the communications between musculocutaneous and median nerves in to three types considering the coracobrachialis muscle as the reference point.

Type l: the communication was proximal to the entrance of the musculocutaneous nerve in to the muscle.

Type II: the communication was distal to the muscle.

Type III: the nerve and the communicating branch did not pierce the muscle.

Significant variations in nerve patterns may be the result of altered signalling between mesenchymal and neuronal growth cones ${ }^{8}$ or circulatory factors at the time of fusion of brachial plexus cords ${ }^{9}$. The presence of such nerve communications are not just confined to man, studies on comparative anatomy have reported the existence of such

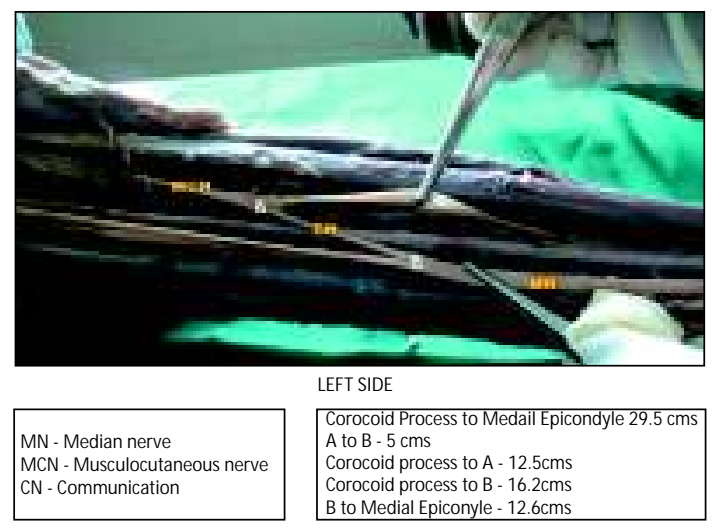

References:

1. Alnot JY, Huten B. Systematisation of the brachial plexus. Rev Chir Orthop Reparatrice Appar M ot 1977; 68: 27-34.

2. Standring S. Gray's anatomy. The anatomical basis of clinical practice. 39th ed. London: Elsevier Churchill Livingstone; 2005.

3. Venieratos D, Anagnostopoulou S. Classification of communications between the musculocutaneous and median nerves. Clin Anat 1998; 11: 327-331.

4. Eglseder WA Jr, Goldman M. Anatomic variations of the musculocutaneous nerve in the arm. Am J Orthop (Belle Mead $\mathrm{NJ}$ ). 1997; 26: 777-780.

5. Loukas M, Aqueelah H. Musculocutaneous and median nerve connections within, proximal and distal to the coracobrachialis muscle. Folia M orphol (Warsz). 2005; 64: 101-108. connections in monkeys and in some apes. Thus suggesting that communications may represent the primitive nerve supply of anterior arm muscles ${ }^{10}$.

\section{Conclusion:}

Communications between musculocutaneous nerve and median nerve may be of considerable significance to neurologists and orthopaedicians when dealing with patients of nerve entrapment syndromes of the upper $\operatorname{limb}^{11}$. Anatomical variations of peripheral nerves have clinical and surgical importance especially in posttraumatic evaluations and exploratory interventions of the arm for peripheral nerve repair and to some extent during flap dissections. Finally, although anterior approach for internal fixation of humeral fractures seems to be safer than the posterior approach because of high risk of radial nerve damage in posterior approach. Thus precise knowledge of variations in musculocutaneous nerve and median nerve may prove valuable in traumatology of the arm, as well as in plastic and reconstructive repair operations. If the surgeons find it necessary to isolate and trace the median nerve and musculocutaneous nerve distally, it is essential to be alert to the communications that may occur between them.

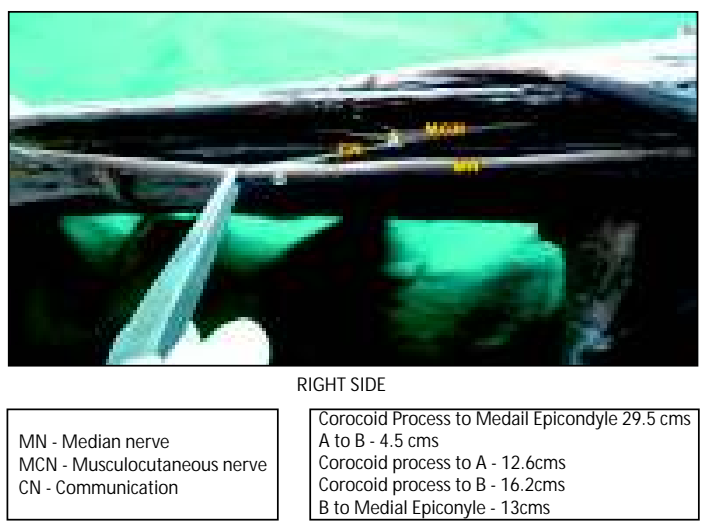

6. Prasada Rao PV, Chaudhary SC. Communication of the musculocutaneous nerve with the median nerve. East Afr M ed J. 2000; 77: 498-503.

7. Chauhan R, Roy TS. Communication between the median and musculocutaneous nerve - a case report. J Anat Soc India. 2002; 51: $72-75$.

8. Kosugi K, Morita T, Koda M, Yamashita H. Branching pattern of the musculocutaneous nerve. 1. Case possessing normal biceps brachii. Jikeikai M ed J. 1986; 33: 63-71.

9. Sanes HD, Reh TA, Harris WA. Development of the nervous system. 1st Ed. New York, Academic Press. 2000; 189-197.

10. Miller RA. Comparative studies upon the morphology and distribution of the brachial plexus. AmJ Anat.1934; 54: 143-175.

11. M oore KL, Dalley AF. Clinically oriented anatomy. 4th ed. Philadelphia: Lippincott Williams\& Wilkins; 1999. 